\section{Zinc transporter 8 autoantibodies in patients with type 1 diabetes from a multiethnic population and their first degree relatives}

\author{
Autoanticorpos transportadores de zinco 8 em \\ pacientes com diabetes tipo 1 de uma população \\ multiétnica e seus parentes de primeiro grau
}

Débora Batista Araujo"1, Hanna Skärstrand "2, Bianca Barone', Joana

Rodrigues Dantas', Rosane Kupfer ${ }^{3}$, Lenita Zajdenverg' ', Adolpho Milech',

Fariba Vaziri-Sani', José Egídio Paulo de Oliveira', Melanie Rodacki'

\begin{abstract}
Objective: Zinc transporter 8 autoantibodies (ZnT8A) have been poorly studied in non-Caucasian individuals. We aimed to investigate the prevalence of ZnT8 autoantibodies in patients with T1D and their first degree relatives (FDR) from a multiethnic population, as well as its relation with the insulin (INS) or the protein tyrosine phosphatase non-receptor 22 (PTPN22) gene polymorphisms. Subjects and methods: ZnT8A were analyzed in sera from T1D patients ( $n=72$, mean age of $30.3 \pm 11.4$ years) of variable duration $(15.7 \pm 11.8$ years) and their FDR $(n=$ 78 , mean age of $18.3 \pm 9.1$ years) by a triple mix Radioligand Binding Assay (RBA) for the ZnT8 autoantibody (ZnT8-RWQ) variants. SNP (single nucleotide polymorphism) for INS and PTPN22 were genotyped. Results:The prevalence of ZnT8A was higher in T1D patients than FDR, for ZnT8TripleA (24\% vs. 4\%,p = 0.001), ZnT8RA (24\% vs. 4\%, p< 0.001) and ZnT8QA (15\% vs. 3\%, $p=0.004)$. All FDR with ZnT8A ( $n=3)$ had at least another positive antibody. Heterozygosis for PTPN22 was associated with a higher frequency of ZnT8TripleA $(p=0.039)$ and ZnT8RA ( $p=$ 0.038). Conclusions: ZnT8A is observed in non-Caucasian patients with T1D, even years after the disease onset, as well as in their FDR. In those, there was an overlap between ZnT8A and otherT1D antibodies. ZnT8A was associated with PTPN22 polymorphisms. Further longitudinal studies are necessary to elucidate the importance of these findings in the natural history ofT1D patients with multiethnic background. Arq Bras Endocrinol Metab. 2014;58(7):737-43
\end{abstract}

Keywords

Autoimmunity; diabetes; non-whites; ZnT8A; PTPN22

\section{RESUMO}

Objetivo: Os autoanticorpos transportadores de zinco 8 (ZnT8A) foram pouco estudados em indivíduos não caucasianos. Nosso objetivo foi investigar a prevalência de autoanticorpos ZnT8 em pacientes com T1D e seus parentes de primeiro grau (PPG) em uma população multiétnica, assim como a sua relação com os polimorfismos genéticos da insulina (INS) ou proteína tirosina fosfatase não receptora tipo 22 (PTPN22). Sujeitos e métodos: ZnT8A foram analisados no soro de pacientes com T1D ( $n=72$, idade média de $30,3 \pm 11,4$ anos) de duração variável (15,7 $\pm 11,8$ anos) e seus PPG ( $n=72$, idade média de 30,3 $\pm 11,4$ anos) usando-se um ensaio de competição com radioligantes (RBA) para variantes dos autoanticorpos ZnT8 (ZnT8-RWQ). Os polimorfismos de nucleotídeo único para a INS e PTPN22 foram genotipados. Resultados: A prevalência de ZnT8A foi mais alta em pacientesT1D do que nos PPG, para ZnT8TriploA (24\% contra 4\%, $p=0,001)$, ZnT8RA ( $24 \%$ contra $4 \%, p<0,001$ ) e ZnT8QA ( $15 \%$ contra $3 \%, p=0,004)$. Todos os PPG com ZnT8A ( $n=3$ ) apresentaram positividade para pelo menos outro anticorpo. A heterozigose para PTPN22 foi associada a uma frequência mais alta de ZnT8TriploA ( $p=0,039$ ) e de ZnT8RA ( $p=0,038$ ). Conclusões: Os ZnT8A foram observados em pacientes não caucasianos comT1D, mesmo depois de anos do início da doença, assim como em seus PPG. Nos parentes, houve uma sobreposição entre os ZnT8A e outros anticorpos para T1D. Os ZnT8A mostraram-se associados aos polimorfismos PTPN22. São necessários outros estudos longitudinais para se elucidar a importância desses achados na história natural de pacientes com T1D com antecedentes étnicos variados. Arq Bras Endocrinol Metab. 2014;58(7):737-43
1 Department of Nutrology, Universidade Federal do Rio de Janeiro (UFRJ), Rio de Janeiro, RJ, Brazil

${ }^{2}$ Department of Clinical Sciences, Lund University, Skäne University Hospital (SUS), Malmö, Sweden ${ }^{3}$ Instituto Estadual de Diabetes e Endocrinologia Luiz Capriglione (IEDE), Rio de Janeiro, RJ, Brazil

* Débora Batista Araujo and Hanna Skärstrand contributed equally to this manuscript

Correspondence to: Débora Batista Araujo Av. Epitácio Pessoa, 3.540, ap. 903 22471-003 - Rio de Janeiro, RJ, Brazil dbatistaaraujo@gmail.com

Received on Oct/22/2013 Accepted on June/29/2014

DOI: 10.1590/0004-2730000003088 


\section{INTRODUCTION}

$\mathrm{T}$ ype 1 diabetes (TID) is a chronic disease characterized by an autoimmune destruction of the pancreatic islet $\beta$ cells $(1,2)$. The immunogenetic and environmental factors associated with the initiation and progression of TID are not yet fully understood. However, elucidation of these issues is crucial for possible prevention and treatment of TID. Most investigations regarding the course of TID in humans have included only Caucasians, therefore very little is known about the natural history of TID in other ethnic groups.

Autoantibodies against insulin, glutamic acid decarboxylase 65 (GAD65) and islet antigen-2 (IA2) are important predictive markers preceding clinical onset of TlD $(2,3)$. Zinc Transporter 8 (ZnT8) protein was recognized as one of the four major autoantigens in TID patients (4) and to which autoantibodies are generated prior to the clinical onset of T1D. ZnT8 autoantibodies (ZnT8A) have been demonstrated to substantially overlap with the prevalence of IA2A, in particular (5). Moreover, a significant correlation of the prevalence of ZnT8A and IA2A has been proven in TID patients (6).

ZnT8A have been suggested to be directed against at least two epitopes found in relation to the single amino acid in position 325 expressed on the $\mathrm{C}$-terminal portion of the protein, and less frequently against the $\mathrm{N}$-terminal portion $(4,5)$. The description of the single nucleotide polymorphism (SNP) rs13266634 in the gene of ZnT8, SLC30A8, is explaining an amino acid change in position 325 from arginine (CGG) to tryptophan (TGG) (7). In addition, the SNP rs16889462 at the same amino acid position in SLC30A8 encodes glutamine (CAG). To date, there are three variants of ZnT8A detected in TID patients, ZnT8RA (arginine), ZnT8WA (tryptophan) and ZnT8QA (glutamine) (8-10). The autoantibody specificity of ZnT8RA and ZnT8WA, respectively, has been shown to be determined by the rs13266634 genotype $(5,6)$. In addition, the ZnT8RA variant was associated with the high risk HLA-DQB1*0302 genotypes (6).

The amino acid residues of ZnT8 are not equally prevalent in populations although the ZnT8RA variant is most common with a prevalence of $75 \%$ in European Caucasians, 98\% in African Americans, and 50\% in Asians (11). $\mathrm{ZnT} 8 \mathrm{~W}$ is prevalent in 25\% of Europeans, $2 \%$ of African Americans, and in nearly $50 \%$ of Asians compared to the ZnT8Q variant, which is rarely found in Europeans and Asian but in 9\% of the African American population (11).

The protein tyrosine phosphatase, non-receptor type 22 (PTPN22) gene encodes a protein tyrosine phos- phatase expressed in the lymphoid (LYP) $(12,13)$. The importance of the PTPN22 gene and the mechanisms of SNP R620W (rs2476601) are not fully understood, although it has previously been evident as genetic predisposition risk marker for autoimmune diseases, such as TID and rheumatoid arthritis (12-14). It has been postulated that carriers of the PTPN22 SNP R620W may have a disrupted suppression of T-cell activation (15), resulting in an overactive T-cell response (16).

The aim of this study was to evaluate the prevalence of ZnT8 autoantibodies, as well as its association with insulin (INS) gene and protein tyrosine phosphatase non-receptor 22 (PTPN22) gene polymorphisms in multiethnic Brazilian patients with TID and their first degree relatives (FDR).

\section{SUBJECTS AND METHODS}

\section{Subjects}

Brazilian patients with TID $(\mathrm{n}=72)$ and their FDR $(\mathrm{n}=78)$ were interviewed and blood was sampled for DNA extraction and autoantibody measurement. TID was defined according to the American Diabetes Association criteria. One participant per family was included. Participants were classified as whites and non-whites (mostly Afro-descendants) based on their phenotype and family background. Although white individuals in this population have predominantly Caucasian ancestry, they could not be classified as pure Caucasians due to miscegenation in past generations (17). The project was approved by the institutional review board and all participants signed an informed consent.

Serum samples were analyzed by a standard radioligand binding assay (RBA) for the three individual $\mathrm{Zn}$ T8A variants (ZnT8RA, ZnT8WA, ZnT8QA) as well as with the ZnT8TripleA assay, which both were developed at the Department of Clinical Sciences, Skäne University Hospital, Malmö, Sweden. The RBA for GAD, insulin and tyrosine phosphatase A (GADA, IAA and IA2A, respectively) were performed at the Federal University of Rio de Janeiro, Rio de Janeiro, Brazil.

\section{Generation of ZnT8R, ZnT8W, ZnT8Q constructs}

The C-terminal cDNA was constructed with arginine at amino acid 325 from human islet ZnT8 (SLC30A8) (gift from Dr. J. C. Hutton at Barbara Davis Center for Childhood Diabetes, University of Colorado at Denver and Health Sciences Center, Aurora, CO). The gene- 
ration of the $\mathrm{ZnT}$ 8 constructs is described in detail by Vaziri-Sani and cols. (18). Briefly, the ZnT8R construct of amino acid (aa) 268-369 was subcloned into the $\mathrm{pTnT}^{\mathrm{PM}}$ vector (Promega, Madison, USA) and was further used as a template in a Phusion ${ }^{\mathrm{TM}}$ site-directed mutagenesis kit (Finnzymes Oy, Espoo, Finland) to generate additional plasmids, pThZnT8W and pThZnT8Q $(6,9,10)$.

\section{Radioligand binding assay (RBA)}

The RBA detection of all three ZnT8A variants was carried out as described elsewhere (18). Briefly, the recombinant ${ }^{35} \mathrm{~S}$-methionine labeled $\mathrm{ZnT} 8$ protein variants of cytosolic segments (aa 268-369) were produced using the coupled in vitro transcription translation system (Promega, Madison, WI). Sera $(5 \mu \mathrm{L})$ were incubated with $60 \mu \mathrm{L}$ labeled ZnT8 autoantigen overnight at $4^{\circ} \mathrm{C}$ at $300 \mathrm{rpm}$ and separated by precipitation using Protein A Sepharose (Invitrogen, Carlsbad, CA). Antibody-bound radioactivity was counted in a $\beta$-counter (1450 MicroBeta TriLux Microplate Scintillation-Luminescence Counter) and converted into the in-house units (U) using individual standard curves generated by six step doubling dilutions of high-titer TID sera with high reactivity for each individual ZnT8 autoantigen. For the ZnT8ATriple assay, sera were incubated with a mixture of all three labeled $\mathrm{ZnT}$ 8 variants (ZnT8R, ZnT8W and ZnT8Q) at equal concentrations. Cut-off values for the positive test were set to $75 \mathrm{U} / \mathrm{mL}$ for ZnT8RA and ZnT8WA, $100 \mathrm{U} / \mathrm{mL}$ for ZnT8QA and $60 \mathrm{U} / \mathrm{mL}$ for the ZnT8ATriple assay. Cut-off values were based on the $98^{\text {th }}$ percentile observed in 398 healthy adult controls from Malmö, Sweden.

Titers of the three ZnT8A variants and ZnT8TripleA were measured for both TID patients and their FDR. The titers of GADA, IAA and IA2A were measured only in samples from FDR.

\section{Genetic analysis}

The TID patients and their FDR were genotyped for INS gene and PTPN22 polymorphisms. SNP for INS and PTPN22 (polymorphism RS620W rs2476601) were genotyped with fluorogenic allele-discrimination chemistry as described elsewhere $(14,16,19)$.

\section{Statistical analysis}

Mann-Whitney $U$ test and chi-square were used for comparison between groups. Spearman coefficient was used to test correlation between continuous variables, and Fisher's exact t-test to test correlation between categorical variables. A p-value $<0.05$ was considered significant.

\section{RESULTS}

\section{Epidemiological and genetic characteristics of the study group}

The characteristics of the study group are described in table 1 . TlD subjects were older (mean \pm SD years, $30.3 \pm 11.4$ ) than the FDR (mean \pm SD years, $18.3 \pm$ 9.1) participating in the study. The median age of T1D onset was $18.6 \pm 11.6$ years and its duration varied from 1 to 30.5 years (mean \pm SD years, $15.7 \pm 11.8$ ).

\section{ZnT8A profile in the T1D patients and FDR}

The prevalence of ZnT8As was higher in TID patients than in FDR, for ZnT8TripleA (24\% vs. 4\%, p = 0.001), ZnT8RA (24\% vs. 4\%, p < 0.001) and ZnT8QA (15\% x $3 \%, \mathrm{p}=0.004)$. For ZnT8WA no difference was found (8.3\% vs. $2.6 \% ; \mathrm{p}=0.154)$ between groups (Table 1$)$. ZnT8RA were most prevalent in both TID patients and FDR (Table 1). Among the TID patients, 5.5\% $(\mathrm{n}=4)$ had ZnT8RA alone (Figure 1$)$ compared to $1.3 \%(\mathrm{n}=1)$ in the FDR (Figure 2), and $11 \%(\mathrm{n}=8)$ had autoantibodies against all three ZnT8A variants compared to $2.6 \%$ $(\mathrm{n}=2)$ in the FDR. In those with positive antibodies, the titer levels of ZnT8ATriple ( $\mathrm{p}=0.030), \mathrm{ZnT}$ RRA ( $\mathrm{p}$ $=0.006)$ and ZnT8WA $(\mathrm{p}=0.01)$ were also higher in patients compared to the FDR. This was not true for the ZnT8QA titers. ZnT8A positivity or its titers were not associated with ethnicity in either groups (Positivity: $\mathrm{p}=$ 0.783 for patients and $\mathrm{p}=0.557$ for FDR; titers 117.1 $\mathrm{U} / \mathrm{ml} \pm 369.2$ for patients and $71.1 \mathrm{U} / \mathrm{ml} \pm 426.3$ for FDR) and did not show any association with the presence of diabetic ketoacidosis at diagnosis $(\mathrm{p}=0.574)$.

There were no differences in the frequency nor the titers of any of the autoantibody variants $(\mathrm{p}=0.507$ for ZnT8ATriple, $\mathrm{p}=0.507$ for ZnT8RA, $\mathrm{p}=0.119$ for ZnT8WA and $\mathrm{p}=0.112$ for ZnT8QA) between patients who had diabetes for less than five years $(n=16)$ compared to those with a longer disease duration ( $\mathrm{n}$ = 56). However, for ZnT8QA there was a trend towards higher titers in the former group than the latter ( $\mathrm{p}=0.056 ; 204.68 \mathrm{U} / \mathrm{mL} \pm 523.95$ vs. $39.64 \mathrm{U} / \mathrm{mL}$ $\pm 65.45)$. ZnT8A positivity was seen in a patient with 30.5 years of disease. 
Table 1. Epidemiological and genetic characteristics of type 1 diabetes patients and their first degree relatives (FDR)

\begin{tabular}{|c|c|c|c|}
\hline Characteristics & $\begin{array}{c}\text { T1D patients } \\
\mathrm{n}=72(\%)\end{array}$ & $\begin{array}{c}\text { FDR } \\
\mathbf{n}=\mathbf{7 8}(\%)\end{array}$ & $p$ value \\
\hline Age (mean $\pm S D$ years) & $30.3 \pm 11.4$ & $18.3 \pm 9.1$ & $<0.001$ \\
\hline Age onset (mean $\pm \mathrm{SD}$ years) & $18.6 \pm 11.6$ & - & - \\
\hline Duration of T1D (mean \pm SD years) & $15.75 \pm 11.8$ & - & - \\
\hline $\begin{array}{l}\text { Gender n (\%) } \\
\text { Female }\end{array}$ & $49(68)$ & $45(57.7)$ & 0.419 \\
\hline \multicolumn{4}{|l|}{ Ethnicity n (\%) } \\
\hline Whites & $31(43)$ & $31(39.7)$ & 0.751 \\
\hline Non-whites & $41(57)$ & $47(60.3)$ & \\
\hline \multicolumn{4}{|l|}{ INS gene SNP n (\%) } \\
\hline Homozygous T/T & $38(55.9)$ & $29(40.8)$ & 0.201 \\
\hline Heterozygous A/T & $21(30.9)$ & $32(45.1)$ & \\
\hline Polymorphic allele $\mathrm{A}$ & $9(13.2)$ & $10(14.1)$ & \\
\hline Total & $68(100)$ & $71(100)$ & \\
\hline \multicolumn{4}{|c|}{ PTPN22 gene SNP R620W rs2476601 (\%) } \\
\hline Homozygous $\mathrm{C} / \mathrm{C}$ & $56(84.8)$ & $56(93.3)$ & 0.438 \\
\hline Heterozygous $\mathrm{C} / \mathrm{T}$ & $10(15.2)$ & $4(6.7)$ & \\
\hline Homozygous T/T & $0(0)$ & $0(0)$ & \\
\hline Total & $66(100)$ & $60(100)$ & \\
\hline \multicolumn{4}{|l|}{ ZnT8A frequency (\%) } \\
\hline TripleA & $17(23.6)$ & $3(3.8)$ & 0.001 \\
\hline ZnT8RA & $17(23.6)$ & $3(3.8)$ & $<0.001$ \\
\hline ZnT8WA & $10(13.9)$ & $2(2.6)$ & 0.154 \\
\hline ZnT8QA & $6(8.3)$ & $2(2.6)$ & 0.004 \\
\hline Total & $72(100)$ & $78(100)$ & \\
\hline \multicolumn{4}{|c|}{ ZnT8A titers (U/ml) (mean $\pm \mathrm{SD}$ ) (median) } \\
\hline TripleA & $117.1 \pm 369.2 ; 15,00$ & $71.1 \pm 426.3 ; 11,00$ & 0.030 \\
\hline ZnT8RA & $173.5 \pm 454.4 ; 18,00$ & $97.1 \pm 491.3 ; 15,50$ & 0.006 \\
\hline ZnT8WA & $59.7 \pm 267.9 ; 21,00$ & $45.5 \pm 294.4 ; 14,00$ & 0.010 \\
\hline ZnT8QA & $76.3 \pm 257.0 ; 12,00$ & $48.3 \pm 251.5 ; 9,00$ & 0.095 \\
\hline
\end{tabular}

72 T1D subjects and 78 FDR subjects were analyzed for ZnT8ATriple, ZnT8RA, ZnT8WA and ZnT8QA. T1D patients $(n=68)$ and FDR $(n=71)$ were analyzed for the INS gene SNP. T1D patients ( $\mathrm{n}$ $=66)$ and FDR $(n=60)$ were analyzed for PTPN22 gene SNP R620W (rs2476601).

T1D: type 1 diabetes; INS: insulin; PTPN22: protein tyrosine phosphatase non-receptor 22; ZnT8A: Zinc transporter 8 autoantibody.

P-value $<0.05$ was considered significant.

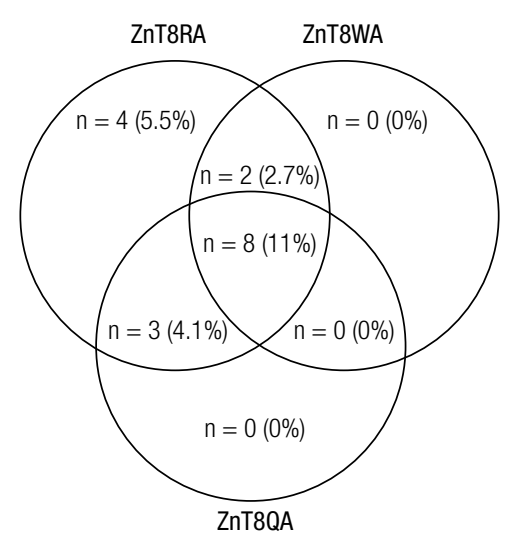

Figure 1. The prevalence of Zinc transporter 8 autoantibodies (ZnT8A) against ZnT8-Arginine (R), ZnT8-Tryptophane (W) and ZnT8-Glutamine (Q) in type 1 diabetes patients (T1D) $(n=72)$ analyzed by an individual Radioligand binding assay (RBA). Among the T1D patients $11 \%(n=8)$ had all three ZnT8 autoantibodies.

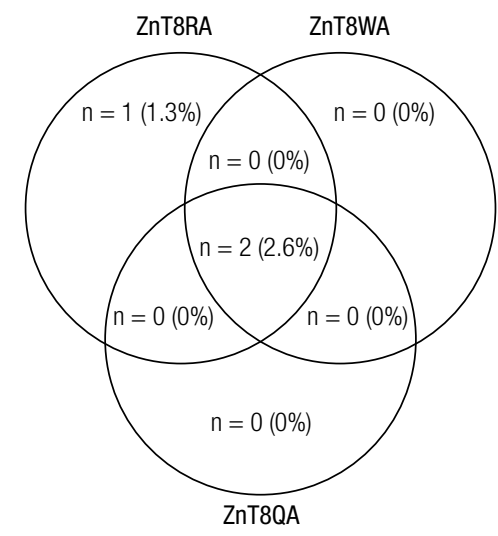

Figure 2. The prevalence of ZnT8 autoantibody (ZnT8A) variants, ZnT8Arginine (R), ZnT8-Tryptophane (W) and ZnT8-Glutamine $(\mathrm{Q})$ in first degree relatives (FDR) $(n=78)$ to T1D patients analyzed by an individual Radioligand binding assay (RBA). Among the FDR $2.6 \%$ were positive for all three ZnT8A variants. 


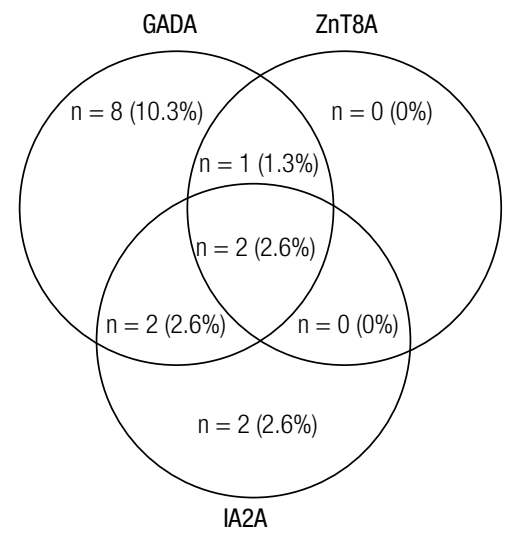

Figure 3. Prevalence of autoantibodies against Glutamic acid decarboxylase (GADA), Zinc transporter 8 (ZnT8) (any of the variants) and insulinoma-associated protein 2 (IA2) analyzed in first degree relatives (FDR) $(n=78)$ to T1D patients. GADA were most prominent $(10.3 \%)$ of the three GADA, ZnT8A and IA2A autoantibody types, while all of them were detected in $2.6 \%$ of the FDR.

\section{Overlap of ZnT8A prevalence with other islet autoantibodies in FDR}

GADA, IA2A and IAA were tested in FDR of patients with TID. One or more autoantibodies (GADA, IA2A and one, two or all variants of $\mathrm{ZnT}$ 8A) were found in $15.6 \%$ of the FDR. GADA was detected in $10 \%(\mathrm{n}=$ $8)$ and IA2A in $2.6 \%(\mathrm{n}=2)$. These results are shown in figure 3. In antibody positive $(\mathrm{Ab}+) \mathrm{FDR}$, the mean titers of GADA and IA2A were $23.9 \mathrm{U} / \mathrm{mL}$ (SD 25.1 $\mathrm{U} / \mathrm{mL}$ ) and $5.8 \mathrm{U} / \mathrm{mL}(\mathrm{SD} 5.4 \mathrm{U} / \mathrm{mL})$, respectively. Among $\mathrm{Ab}+\mathrm{FDR}$, we found a positive association between GADA and ZnT8TripleA $(\mathrm{p}=0.001)$ as well as with all individual variants, ZnT8RA $(\mathrm{p}=0.001)$, ZnT8WA $(\mathrm{p}=0.002)$ and ZnT8QA $(\mathrm{p}=0.012)$. Similar overlap was seen for IA2A with the ZnT8TripleA $(\mathrm{p}=$ 0.007), ZnT8RA ( $=0.006)$, ZnT8WA ( $=0.002)$ and ZnT8QA ( $\mathrm{p}=0.012)$. Only one FDR was positive for IAA and no association was found with the three $\mathrm{ZnT} 8 \mathrm{~A}$ variants. The number of $\mathrm{Ab}+$ individuals did not increase with the inclusion of ZnT8A measurement.

\section{Association between ZnT8A and the PTPN22 polymorphism}

The genotype distribution of the INS gene ( $\mathrm{n}=139$, $\mathrm{T} / \mathrm{T} 48.2 \%, \mathrm{~A} / \mathrm{T} 38.1 \%, \mathrm{~A} / \mathrm{A} 13.7 \%$ ) and the PTPN22 ( $\mathrm{n}=126, \mathrm{C} / \mathrm{C} 88.9 \%, \mathrm{C} / \mathrm{T} 11.1 \%, \mathrm{~T} / \mathrm{T} 0 \%)$ including both patients and FDR were heterogeneous $(\mathrm{p}=0.201$ for INS, $\mathrm{p}=0.438$ for PTPN22) (Table 1 ).

Interestingly, we found an association between PTPN22 genotype and the prevalence of ZnT8 antibo- dies. Heterozygotes for PTPN22 had a higher frequency of ZnT8TripleA $(35.7 \%$ vs. $12.61 \%$; $\mathrm{p}=0.039)$ and also with the individual ZnT8RA (35.7\% vs. $12.5 \%$; $\mathrm{p}=$ 0.038 ), but not of ZnT8WA (7.1\% vs. 5.4\%; $\mathrm{p}=0.571$ ) nor ZnT8QA (21.4\% vs. 8.9\%; p = 0.159). Moreover, heterozygotes for PTPN22 had higher titers of all ZnT8 antibodies $(327.9 \mathrm{U} / \mathrm{mL} \pm 778.9$ vs. $79.6 \pm 366.5$ and $\mathrm{p}=0.014$ for ZnT8TripleA; $506.14 \mathrm{U} / \mathrm{ml} \pm 1037.1 \mathrm{vs}$. $110.6 \pm 393.1$ and $\mathrm{p}=0.002$ for ZnT8RA, $191.28 \mathrm{U} /$ $\mathrm{mL} \pm 597.7 v s .43 .1$ and $\mathrm{p}=0.03$ for ZnT8WA; 207.8 \pm 563.3 vs. $51.2 \pm 213.9$ and $\mathrm{p}=0.048$ for $\mathrm{ZnT} 8 \mathrm{QA}$ ). However, when patients and FDRs were analyzed separately, the association between PTPN22 polymorphism and ZnT8A was not seen in either of the groups.

\section{DISCUSSION}

In this study, we investigated the prevalence of ZnT8 autoantibodies in patients with TID and their FDR with multiethnic background, as well as its relation to the INS and PTPN22 gene polymorphisms. As the majority of studies in this field include white Caucasians or Asiatics, the immunogenetic profile of Afro-descendants remains unclear. Therefore, analysis of this group is especially interesting.

In our population, Znt8A prevalence was lower than previously reported in Caucasians FDR of patients with TID (4\% vs. $24 \%)(4,9,10)$, but similar to that reported in Asiatics (27). The most prevalent ZnT8A variant was the autoantibody directed against arginine, which is in concordance with Wenzlau and cols. (8). Among the FDR with positivity for ZnT8A, all had the variant arginine, suggesting that this epitope is the most important in our population. In FDR of patients with TID with multiethnic background, the measurement of ZnT8A did not improve the stratification for TID risk, as all individuals were positive for ZnT8A and GADA concomitantly. In FDR, there was an overlap not only of ZnT8A (all variants) and GADA, but also IA2A. Previous studies have reported similar findings at the onset of TID in Caucasian patients $(4,9,20,29)$ and FDR $(26,30)$. Therefore, ZnT8A can be considered a marker for TID autoimmunity not only in Caucasians, but also in multiethnic populations such ours, although it does not seem to improve the identification of FDR in risk of TID when added to GADA, IA2A and IAA.

Interestingly, ZnT8A was detected among TID patients even many years after diagnosis, which was previ- 
ously shown by Yang and cols. in the Chinese population (27). However, Howson and cols. demonstrated a higher prevalence of $\mathrm{ZnT}$ 8A in the first two years of the disease (31). The factors involved in the maintenance of serum ZnT8A are still to be identified, but this characteristic makes the measurement of this antibody particularly useful in patients with long-standing diabetes and unclear diabetes classification, where the identification of an autoimmune marker can establish the definite diagnosis. Moreover, Trabucchi and cols. have shown that a significant proportion of autoimmune adult-onset diabetic patients present ZnT8A as the only humoral marker (32).

A major finding in our study was the association between PTPN22 and ZnT8RA in a multiethnic population, which differ from previous data $(31,33)$. Although we did not find any correlation between PTPN22 genotype and ZnT8A in each group individually (patients or FDR), this may be due to the limited size sample. Other authors did not show a similar association. Sorgjerd and cols. identified a trend for an association between ZnT8A positivity and the polymorphisms of the SLC30A8 gene (28). For Howson and cols., only FCRL3 on chromosome lq23.1 and the HLA class I region were associated with positivity for ZnT8A (31). The association between SLC3A08 and ZnT8WA has also been reported by Delli and cols. in Swedish patients with T1D (29).

It is possible that there is a link between PTPN22 polymorphism and ZnT8A specifically in our population or other similar ethnic groups. PTPN22 SNP $\mathrm{R} 620 \mathrm{~W}$ is known to mediate the risk for several autoimmune diseases including TID, and may therefore be important in the regulation of autoreactivity in general $(12-14,16)$. PTPN22 has been linked to the presence of other antibodies linked to TID such as GADA and IA2A, both in individuals at risk for TID, as well as short or long-standing disease $(16,22,24)$. However, we did not identify any association of PTPN22 and GADA or IA2A in our cohort of patients (25) and FDR (19) with TID. To our knowledge, this is the first study to identify such correlation between the PTPN22 gene and ZnT8RA, which could be a peculiarity of our population. This association needs to be further investigated in order to elucidate how PTPN22 could be involved in the pathogenesis of TID, which in turn could be useful in future prevention strategies.
In conclusion, $\mathrm{ZnT}$ 8A is observed in non-Caucasian patients with TID, even years after the disease onset, as well as in their FDR. In those, there was an overlap between ZnT8A and other TID antibodies. ZnT8A was associated with PTPN22 polymorphisms. Further longitudinal studies are necessary to elucidate the importance of these findings in the natural history of TID patients with multiethnic background.

Acknowledgements: we thank the participants and their families in this study as well as the nursing and medical staff for their help; Åke Lernmark at the Department of Clinical Sciences, Lund University, Skåne University Hospital SUS, Malmö, Sweden, for his valuable comments on the manuscript.

Hanna Skärstrand and Débora Batista researched the data, analyzed and wrote the manuscript. Bianca Barone, Joana Rodrigues and Rosane Kupfer recruited the patients and researched the data. Fariba Vaziri-Sani, Melanie Rodacki, Lenita Zajdenverg, José Egídio Paulo and Adolpho Milech reviewed and edited the manuscript.

Disclosure: no potential conflict of interest relevant to this article was reported.

\section{REFERENCES}

1. Gale EA. The discovery of type 1 diabetes. Diabetes. 2001;50(2):217-26.

2. Winter WE, Schatz DA. Autoimmune markers in diabetes. Clin Chem. 2011;57(2):168-75.

3. Kulmala $P$, Savola K, Petersen JS, Vähäsalo $P$, Karjalainen J, Löppönen T, et al. Prediction of insulin-dependent diabetes mellitus in siblings of children with diabetes. A population-based study. The Childhood Diabetes in Finland Study Group. J Clin Invest. 1998;101(2):327-36.

4. Wenzlau JM, Juhl K, Yu L, Moua O, Sarkar SA, Gottlieb P, et al. The cation efflux transporter ZnT8 (SIc30A8) is a major autoantigen in human type 1 diabetes. Proc Natl Acad Sci U S A. 2007;104(43):17040-5.

5. Wenzlau JM, Liu Y, Yu L, Moua O, Fowler KT, Rangasamy S, et al. A common nonsynonymous single nucleotide polymorphism in the SLC30A8 gene determines ZnT8 autoantibody specificity in type 1 diabetes. Diabetes. 2008;57(10):2693-7.

6. Brorsson C, Vaziri-Sani F, Bergholdt R, Eising S, Nilsson A, Svensson $\mathrm{J}$, et al. Correlations between islet autoantibody specificity and the SLC30A8 genotype with HLA-DQB1 and metabolic control in new onset type 1 diabetes. Autoimmunity. 2011;44(2):107-14.

7. Sladek R, Rocheleau G, Rung J, Dina C, Shen L, Serre D, et al. A genome-wide association study identifies novel risk loci for type 2 diabetes. Nature. 2007;445(7130):881-5.

8. Wenzlau JM, Moua O, LiuY, Eisenbarth GS, Hutton JC, Davidson HW. Identification of a major humoral epitope in SIc30A8 (ZnT8). Ann NY Acad Sci. 2008;1150:252-5.

9. Vaziri-Sani F, Oak S, Radtke J, Lernmark A, Lynch K, Agardh CD, et al. ZnT8 autoantibody titers in type 1 diabetes patients decline rapidly after clinical onset. Autoimmunity. 2010;43(8):598-606.

10. Andersson C, Larsson K, Vaziri-Sani F, Lynch K, Carlsson A, Cedervall $E$, et al. The three ZNT8 autoantibody variants together improve the diagnostic sensitivity of childhood and adolescent type 1 diabetes. Autoimmunity. 2011;44(5):394-405. 
11. Wenzlau JM, Frisch LM, Gardner TJ, Sarkar S, Hutton JC, Davidson HW. Novel antigens in type 1 diabetes: the importance of ZnT8. Curr Diab Rep. 2009;9(2):105-12.

12. Van Belle TL, Coppieters KT, Von Herrath MG. Type 1 diabetes: etiology, immunology and therapeutic strategies. Physiol Rev. 2011;91:79-118.

13. Bottini N, Musumeci L, Alonso A, Rahmouni S, Nika K, Rostamkhani $\mathrm{M}$, et al. A functional variant of lymphoid tyrosine phosphatase is associated with type I diabetes. Nat Genet. 2004;36:337-8.

14. Begovich AB, Carlton VEH, Honigberg LA, Schrodi SJ, Chokkalingam $\mathrm{AP}$, Alexander $\mathrm{HC}$, et al. A missense single-nucleotide polymorphism in a gene encoding a protein tyrosine phosphatase (PTPN22) is associated with rheumatoid arthritis. Am J Hum Genet. 2004;75:330-7.

15. Hasegawa K, Martin F, Huang G, Tumas D, DiehI L, Chan AC. PEST domain-enriched tyrosine phosphatase (PEP) regulation of effector/memoryT cells. Science. 2004;303:685-9.

16. Bottini N, Vang T, Cucca F, Mustelin T. Role of PTPN22 in type 1 diabetes and other autoimmune diseases. Semin Immunol. 2006;18:207-13.

17. Telles EE. Racial classification, race in another America: the significance of skin color in Brazil. Princeton, NJ: University Press. 2004. p. 81-4.

18. Vaziri-Sani F, Delli AJ, Elding-Larsson $H$, Lindblad B, Carlsson $A$, Forsander $G$, et al. A novel triple mix radiobinding assay for the three ZnT8 (ZnT8-RWQ) autoantibody variants in children with newly diagnosed diabetes. J Immunol Methods. 2011;371:25-37.

19. Barone B, Dantas JR, Almeida MH, Anna-Gomes BS, Bencke-Gongalves MDR, Albernaz MS, et al. Pancreatic autoantibodies, HLA DR and PTPN22 polymorphisms in first degree relatives of patients with type 1 diabetes and multiethnic background. Exp Clin Endocrinol Diabetes. 2011;119(10):618-20.

20. Lampasona V, Petrone A, Tiberti C, Capizzi M, Spoletini M, di Pietro $\mathrm{S}$, et al. Zinc transporter 8 antibodies complement GAD and IA-2 antibodies in the identification and characterization of adult-onset autoimmune diabetes: Non Insulin Requiring Autoimmune Diabetes (NIRAD) 4. Diabetes Care. 2010;33(1):104-8.

21. Barrett JC, Clayton DG, Concannon P, Akolkar B, Cooper JD, Erlich HA, et al. Genome-wide association study and meta-analysis find that over 40 loci affect risk of type 1 diabetes. Nat Genet. 2009;41(6):703-7.

22. Steck AK, Bugawan TL, Valdes AM, Emery LM, Blair A, Norris JM, et al. Association of non-HLA genes with type 1 diabetes autoimmunity. Diabetes. Diabetes. 2005;54(8):2482-6.
23. Chelala C, Duchatelet $S$, Joffret ML, Bergholdt R, Dubois-Laforgue D, Ghandil P, et al. PTPN22 R620W functional variant in type 1 diabetes and autoimmunity related traits. Diabetes. 2007;167:27-33.

24. Maziarz M, Janer M, Roach JC, Hagopian W, Palmer JP, Deutsch K, et al. The association between the PTPN22 $1858 \mathrm{C}>\mathrm{T}$ variant and type 1 diabetes depends on HLA risk and GAD65 autoantibodies. Genes Immun. 2010;11:406-5.

25. Dantas JR, Almeida MH, Barone B, Serfaty F, Raggio LR, Kupfer R, et al. Continuous C-peptide loss in patients with type 1 diabetes and multiethnic background. Diabetes Res Clin Pract. 2013;99(3):e33-6.

26. Yu L, Boulware DC, Beam CA, Hutton JC, Wenzlau JM, Greenbaum $\mathrm{CJ}$, et al. Zinc transporter-8 autoantibodies improve prediction of type 1 diabetes in relatives positive for the standard biochemical autoantibodies. Diabetes Care. 2012;35(6):1213-8.

27. Yang L, Luo S, Huang G, Peng J, Li X, Yan X, et al. The diagnostic value of zinc transporter 8 autoantibody (ZnT8A) for type 1 diabetes in Chinese. Diabetes Metab Res Rev. 2010;26(7):579-84.

28. Sørgjerd EP, Skorpen F, Kvaløy K, Midthjell K, Grill V. Prevalence of ZnT8 antibody in relation to phenotype and SLC30A8 polymorphism in adult autoimmune diabetes: results from the HUNT study, Norway. Autoimmunity. 2013;46(1):74-9.

29. Delli AJ, Vaziri-Sani F, Lindblad B, Elding-Larsson $H$, Carlsson A, Forsander $\mathrm{G}$, et al. Zinc transporter 8 autoantibodies and their association with SLC30A8 and HLA-DO genes differ between immigrant and Swedish patients with newly diagnosed type 1 diabetes in the Better Diabetes Diagnosis study. Diabetes. Diabetes. 2012;61(10):2556-64.

30. Long $A E$, Gooneratne AT, Rokni S, Williams AJ, Bingley PJ. The role of autoantibodies to zinc transporter 8 in prediction of type 1 diabetes in relatives: lessons from the European Nicotinamide Diabetes Intervention Trial (ENDIT) cohort. J Clin Endocrinol Metab. 2012;97(2):632-7.

31. Howson JM, Krause S, Stevens H, Smyth DJ, Wenzlau JM, Bonifacio $\mathrm{E}$, et al. Genetic association of zinc transporter $8(\mathrm{ZnT} 8)$ autoantibodies in type 1 diabetes cases. Diabetologia. 2012;55(7):1978-84.

32. Trabucchi A, Faccinetti NI, Guerra LL, Puchulu FM, Frechtel GD, Poskus $E$, et al. Detection and characterization of ZnT8 autoantibodies could help to screen latent autoimmune diabetes in adult-onset patients with type 2 phenotype. Autoimmunity. 2012;45(2):137-42.

33. Capasso F, Rapini N, Di Matteo G, Testi M, Arcano S, Lidano R, et al. A variable degree of autoimmunity in the pedigree of a patient with type 1 diabetes homozygous for the PTPN22 1858T variant. Pediatr Diabetes. 2013;14(4):304-10. 